\title{
Synergic effect of simvastatin in combination with amphotericin B against environmental strains of Cryptococcus neoformans from northeastern Brazil: a prospective experimental study
}

Tássio Henrique Sousa Silva', Claudiane Vansoski Araújo", Khelvin Myner da Costa Santos"', Nathanael dos Santos Alves'v, Thayse Haylene Soares Gomesv, Andressa Kelly Ferreira e Silvav", Nayra Cristina Lira dos Santos Silvav", Evandro César Bezerra Damasceno Júnior ${ }^{V I I I}$, Andressa Maria Aguiar de Carvalho' ${ }^{1 x}$, Maria Gabriela Araújo Mendes ${ }^{x}$, Henrique Barros Caminha ${ }^{\mathrm{XI}}$, Tatiane Caroline Daboit ${ }^{\mathrm{XII}}$, Thatiana Bragine Ferreira ${ }^{\mathrm{XII}}$, Leonardo Eurípedes Andrade-Silva ${ }^{\mathrm{XIV}}$, Mario León Silva-Vergara ${ }^{\mathrm{xv}}$, Kennio Ferreira-Paim ${ }^{\mathrm{xV}}$, Fernanda Machado FonsecaxvII

Universidade Federal do Piauí, Parnaíba, Piauí, Brazil, in collaboration with Universidade Federal do Triângulo Mineiro, Uberaba, Minas Gerais, Brazil

IBSC. Biomedic, Department of Biomedicine, Universidade Federal do Piauí, Parnaíba (PI), Brazil.

(- orcid.org/0000-0002-7792-2535

"BSc. Biomedic, Department of Biomedicine, Universidade Federal do Piauí, Parnaíba (PI), Brazil.

(0) orcid. org/0000-0002-7763-9190

"BSC. Biomedic, Department of Biomedicine, Universidade Federal do Piauí, Parnaíba (PI), Brazil.

- orcid.org/0000-0002-1550-7512

BSC. Biomedic, Department of Biomedicine, Universidade Federal do Piauí, Parnaíba (PI), Brazil.

๑ orcid.org/0000-0001-6945-6282

'BSc. Biomedic, Department of Biomedicine, Universidade Federal do Piauí, Parnaíba (PI), Brazil.

(-) orcid.org/0000-0003-0369-2690

"BSc. Biomedic, Department of Biomedicine, Universidade Federal do Piauí, Parnaíba (PI), Brazil.

๑ orcid.org/0000-0002-8606-1407

"BSc. Biomedic, Department of Biomedicine, Universidade ederal do Piauí, Parnaíba (PI), Brazil.

(- orcid.org/0000-0002-6067-239X

"IIBSc. Biomedic, Department of Biomedicine, Universidade Federal do Piauí, Parnaíba (PI), Brazil.

- orcid.org/0000-0002-6548-913X

MSc. Doctoral Student, Department of Biomedical Sciences, Universidade Federal do Piaú, Parnaíba (PI), Brazil.

๑ orcid.org/0000-0001-5415-1670

MSc. Doctoral Student, Department of Biomedical Sciences, Universidade Federal do Piaú, Parnaíba (PI), Brazil.

๑ orcid.org/0000-0002-4733-9170

MSc. Doctoral Student, Department of Biomedical Sciences, Universidade Federal do Piauí, Parnaíba (PI), Brazil.

๑ orcid.org/0000-0002-4965-1643

xilPhD. Associate Professor, Department of Medicine,

Universidade Federal do Piauí, Parnaíba (PI), Brazil

๑ orcid.org/0000-0001-5186-7382

"IIMSc. Doctoral Student, Department of Infectious and Parasitic Diseases, Universidade Federal do Triângulo Mineiro, Uberaba (MG), Brazil.

๑ orcid.org/0000-0002-4038-0744

kivphD. Biomedic, Department of Clinical Pathology,

Universidade Federal do Triângulo Mineiro, Uberaba (MG), Brazil.

( orcid.org/0000-0002-0485-229X

PhD. Associate Professor, Department of Infectious and Parasitic Diseases, Universidade Federal do Triângulo Mineiro, Uberaba (MG), Brazil.

(- orcid org/0000-0003-1020-2119

MPhD. Associate Professor, Department of Microbiology,

Universidade Federal do Triângulo Mineiro, Uberaba (MG), Brazi

(- orcid.org/0000-0002-6035-8392

MIPhD. Associate Professor, Department of Biomedicine

Universidade Federal do Triângulo Mineiro, Uberaba (MG), Brazil.

๑ orcid.org/0000-0002-5326-0776

KEY WORDS (MeSH terms):

Cryptococcosis.

Cryptococcus neoformans.

Drug resistance, fungal.

Antifungal agents.

Drug interactions.

AUTHORS' KEY WORDS:

Cryptococcosis treatment

HIV infection.

Fractional inhibitory concentration index

Antifungal therapy.
BACKGROUND: Statins are used as cholesterol-lowering drugs and may also have direct antimicrobial effects.

OBJECTIVE: To evaluate synergic interactions between simvastatin and both amphotericin B and fluconazole, against environmental strains of Cryptococcus neoformans isolated from captive birds' droppings. DESIGN AND SETTING: Experimental study conducted at Federal University of Piauí, Parnaíba, in collaboration with Federal University of Triângulo Mineiro, Uberaba, Brazil.

METHODS: Statin susceptibility tests of Cryptococcus neoformans samples were performed as prescribed in standards. Interactions of simvastatin with amphotericin and fluconazole were evaluated using the checkerboard microdilution method. Presence of these interactions was quantitatively detected through determining the fractional inhibitory concentration index (FICl).

RESULTS: Isolates of Cryptococcus neoformans were obtained from 30 of the 206 samples of dry bird excreta (14.5\%) that were collected from pet shops and houses. Ten isolates were selected for susceptibility tests. All of them were susceptible to amphotericin and fluconazole. All presented minimum inhibitory concentration (MIC) $>128 \mu \mathrm{g} / \mathrm{ml}$ and, thus, were resistant in vitro to simvastatin. An in vitro synergic effect was shown through combined testing of amphotericin B and simvastatin, such that six isolates (60\%) presented $\mathrm{FICl}<0.500$. Two isolates showed considerable reductions in $\mathrm{MIC}$, from $1 \mu \mathrm{g} / \mathrm{ml}$ to $0.250 \mu \mathrm{g} / \mathrm{ml}$. No synergic effect was observed through combining fluconazole and simvastatin.

CONCLUSION: These results demonstrate that simvastatin should be considered to be a therapeutic alternative, capable of potentiating the action of amphotericin B. However, further studies are necessary to clarify the real effect of simvastatin as an antifungal agent.

\section{INTRODUCTION}

Cryptococcus neoformans is an encapsulated and opportunistic yeast fungus that has worldwide distribution. In the urban environment, it is often found in soil contaminated with dried bird excreta, and thus can infect humans and other animals through inhalation. ${ }^{1,2}$

Currently, the treatment for cryptococcosis is based on use of amphotericin B alone or in combination with 5-flucytosine or azoles, in the early stages of the disease. However, the high toxicity associated with these antifungals may restrict their use in special clinical settings, such as in cases of chronic kidney diseases. In situations of secondary prophylaxis, use of fluconazole is indicated to minimize the risk of recurrence of infection in patients who are still in an immunosuppressive state. ${ }^{3}$ Treatment of cryptococcosis using azoles (e.g. fluconazole) requires long periods and can favor the emergence of microbial resistance. Although azoles are less toxic than polyenes, they present low efficacy for the initial treatment of the disease. In contrast, amphotericin B provides a more effective therapeutic response against the fungus, although its use should be limited because of its toxicity. ${ }^{2}$

Emergence of antifungal resistance among environmental and clinical isolates of Cryptococcus neoformans has been described over the last few decades. Prolonged use of antifungals for treating 
patients with immunosuppressive disorders such as acquired immune deficiency syndrome (AIDS) may contribute towards antifungal resistance..$^{4-6}$

Development of new therapeutic strategies is therefore extremely important, given the low number of antifungals available and the scarcity of these drugs in limited-resource settings. In this context, new drugs can contribute towards treatment of cryptococcosis through enhancing the effect of traditional antifungals. ${ }^{7}$

Statins are drugs that are used to treat cardiovascular diseases relating to high cholesterol levels in humans. The mechanism of action of statins is based on inhibition of 3-hydroxy-3-methyl-glutaryl-CoA reductase (HMG-CoA), an enzyme responsible for liver cholesterol biosynthesis. As this enzyme becomes inhibited by statins, the pathway of cholesterol synthesis is blocked, thus resulting in a decrease in LDL cholesterol levels. Additionally, this enzyme synthesizes mevalonic acid, an important precursor in the synthesis of sterols such as ergosterol in fungi and cholesterol in humans. ${ }^{8}$

Hence, statins are important inhibitors of precursors of the synthesis of these sterols. Several studies have demonstrated that some statins present antifungal activity: for example, fluvastatin and simvastatin against species of Candida and Cryptococcus. Therefore, combining statins with antifungal agents could decrease the length of time for which infected patients are exposed to toxic drugs. Consequently, this would reduce the side effects from use of antifungal agents, especially in cases of emergence of fungal strains that are resistant to conventional treatment. ${ }^{9,10}$

In this context, given the increasing numbers of cases of antifungal resistance and the toxicity presented by the conventional treatment scheme, the antifungal potential of simvastatin alone and in association with amphotericin B and fluconazole was tested on Cryptococcus isolates that were recovered from the dried feces of captive birds in northeastern Brazil.

\section{METHODS}

\section{Ethics statement}

This study was approved by the Research Ethics Committee of the Federal University of Piauí (Universidade Federal do Piauí, UFPI), Campus Ministro Reis Velloso, Parnaíba, Piauí, Brazil, under the number CAAE 45296315.5.0000.5669, on July 10, 2015.

\section{Environmental samples}

Between September 2015 and April 2017, a total of 206 dry fecal samples from captive birds of the species Columbia livia, Melopsittacus undulatus and Lonchura striata were collected from pet shops and houses located in different districts of Parnaíba, Piauí, Brazil. This number of samples comprised the total number available for collection at the time of the study. The dried feces were picked up from the birdcages using sterile swabs and were inoculated into tubes containing $10 \mathrm{ml}$ of sterile saline solution with $0.4 \mathrm{~g} / \mathrm{l}$ of chloramphenicol. It was not possible to determine how long these samples had been exposed before the cleaning procedures were performed.

Isolates of Cryptococcus neoformans were obtained from 30 of the 206 samples of dry bird excreta (14.5\%) that had been collected from pet shops and houses. Ten of these isolates were selected for susceptibility tests because all the 30 isolates belonged to the same molecular type.

Each of the 206 feces samples was placed in a separate tube (thus, there were 206 tubes). The tubes were shaken to mix the contents for two minutes and the samples were then left to settle at room temperature for 30 minutes. Next, $100 \mathrm{ml}$ of the supernatant was inoculated onto Niger seed (Guizotia abyssinica) agar plates supplemented with $0.4 \mathrm{~g} / \mathrm{ml}$ of chloramphenicol. Each sample was spread on four plates, incubated at $35^{\circ} \mathrm{C}$ and examined daily for 10 days, macroscopically, in order to identify any presence of smooth, beige to dark brown colonies suggestive of Cryptococcus spp. ${ }^{11}$

These colonies were streaked onto Sabouraud agar at $35^{\circ} \mathrm{C}$ for 48 hours and were identified using the India ink test and urease. Canavanine-glycine-bromothymol blue (CGB) medium was used to differentiate Cryptococcus neoformans from Cryptococcus gattii. The isolates thus obtained (which were clones) were then stored until the tests were performed. To ensure preservation, some of the cell masses were stored in distilled water at $4{ }^{\circ} \mathrm{C}$, while others were stored in yeast peptone dextrose broth (Difco Laboratories, Sparks, MD, USA) with $30 \%$ glycerol at $4{ }^{\circ} \mathrm{C}$.

\section{Deoxyribonucleic acid extraction}

Deoxyribonucleic acid (DNA) extraction was performed as previously described by Bolano et al. ${ }^{12}$ Briefly, a single colony was spread on yeast malt agar (Difco Laboratories) at $37{ }^{\circ} \mathrm{C}$ for 72 hours. Then, a loopful of cells from the culture was transferred to Eppendorf tubes and incubated at $-20^{\circ} \mathrm{C}$ overnight.

Next, $500 \mathrm{ml}$ of cell lysis buffer $[1.25 \mathrm{~mol} / 1 \mathrm{NaCl}, 0.5 \%$ sodium dodecyl sulfate (SDS), $100 \mathrm{mmol} / \mathrm{l}$ Tris-hydrochloride (Tris-HCl) at pH 7.5 and $0.25 \mathrm{~mol} / \mathrm{l}$ ethylenediamine tetraacetic acid (EDTA) at $\mathrm{pH}$ 8.0] and $5 \mathrm{ml}$ of 2-mercaptoethanol (Sigma, Steinheim, Germany) were added. The tubes were vortexed for 2 minutes and incubated at $65^{\circ} \mathrm{C}$ for 1 hour. Then, $500 \mathrm{ml}$ of phenol-chloroform-isoamyl alcohol (25:24:1) was added, shaken for 2 minutes at room temperature and centrifuged at $8150 \mathrm{~g}$, at $4{ }^{\circ} \mathrm{C}$ for 15 minutes.

To precipitate the genomic DNA, the aqueous phase was transferred to a new tube and $500 \mathrm{ml}$ of isopropanol alcohol was added and this mixture was incubated at $-20^{\circ} \mathrm{C}$ overnight. The solution was centrifuged at $4{ }^{\circ} \mathrm{C}$ for 15 minutes at $8150 \mathrm{~g}$ to pellet the DNA and was then washed with ice-cold $70 \%$ ethanol. It was again centrifuged as above and was then air-dried. 
The DNA was resuspended in $500 \mathrm{ml}$ of Tris-EDTA (TE) buffer $(10 \mathrm{mmol} / \mathrm{l}$ Tris- $\mathrm{HCl}$ at $\mathrm{pH} 7.5$ and $0.5 \mathrm{~mol} / \mathrm{l}$ EDTA at $\mathrm{pH} 8.0)$ containing $50 \mathrm{mg} / \mathrm{ml}$ of ribonuclease-A (RNAse-A) (Invitrogen, Carlsbad, CA, USA). It was then incubated at $37^{\circ} \mathrm{C}$ for $30 \mathrm{~min}$ utes and stored at $4{ }^{\circ} \mathrm{C}$ for polymerase chain reactions (PCR) to be performed.

\section{Restriction fragment length polymorphism (RFLP) of URA5 gene}

Amplification of the URA5 gene was carried out in a final volume of $25 \mu \mathrm{l}$. Each reaction contained $10 \mu \mathrm{g}$ of DNA, $2.5 \mu \mathrm{l}$ of 1x PCR buffer $(10 \mathrm{mmol} / \mathrm{l}$ Tris- $\mathrm{HCl}$ at $\mathrm{pH} 8.3,50 \mathrm{mmol} / \mathrm{l} \mathrm{KCl}$ and $1.5 \mathrm{mmol} / 1 \mathrm{MgCl}_{2}$ ), $0.2 \mathrm{mmol} / \mathrm{l}$ each of deoxyadenosine triphosphate (dATP), deoxycytidine triphosphate (dCTP), deoxyguanosine triphosphate (dGTP) and deoxythymidine triphosphate (dTTP), $1.25 \mathrm{U}$ of Taq DNA polymerase (Invitrogen, São Paulo, Brazil) and 25 ng of each primer: URA5 (5'-ATGTCCTCCCAAGCCCTCGACTCCG-3') and SJ01 (5'-TTAAGACCTCTGAACACCGTACTC-3').

From this, a fragment of approximately $800 \mathrm{bp}$ was produced. Thirty-four PCR cycles were performed in a PTC-100 thermocycler (MJ Research Inc., Watertown, MA, USA), consisting of initial denaturation at $94{ }^{\circ} \mathrm{C}$ for 4 minutes, followed by denaturation at $94{ }^{\circ} \mathrm{C}$ for 45 seconds, annealing at $57^{\circ} \mathrm{C}$ for 1 minute, extension at $72{ }^{\circ} \mathrm{C}$ for 1 minute and final extension cycle at $72{ }^{\circ} \mathrm{C}$ for 10 minutes.

The amplified products were mixed with an equal volume of $2 \mathrm{x}$ loading buffer $(0.5 \%$ bromophenol blue, $0.5 \%$ xylene-cyanol and $60 \%$ glycerol) and then separated by means of electrophoresis on $1.5 \%$ agarose gel (Invitrogen, Barcelona, Spain) in 1x Tris-acetateEDTA (TAE) buffer at $90 \mathrm{~V}$ for 2 hours. They were then stained with $0.5 \mathrm{mg} / \mathrm{ml}$ ethidium bromide and viewed under UV light.

Subsequently, $15 \mu \mathrm{l}$ of PCR products were double-digested using Sau $96 \mathrm{I}(10 \mathrm{U} / \mu \mathrm{l})$ and HhaI $(20 \mathrm{U} / \mu \mathrm{l})$ at $37^{\circ} \mathrm{C}$ for 3 hours, and then separated by means of electrophoresis on $3 \%$ agarose gel at $90 \mathrm{~V}$ for 3 hours. RFLP patterns were assigned visually by comparison with the patterns obtained from the standard reference strains (VNI, WM-148; VNII, WM-626; VNIII, WM-628; VNIV, WM-629; VGI, WM-179; VGII, WM-178; VGIII, WM-175; and VGIV, WM-779). ${ }^{13}$ In all the reactions, the reference strain of $C$. neoformans ATCC 90112 (American Type Culture Collection, Manassas, VA, USA) was included as a positive control.

\section{Minimum inhibitory concentration (MIC) and fractional inhibitory concentration index (FICI)}

The broth microdilution test was performed in accordance with the prescriptions of the Clinical and Laboratory Standards Institute (CLSI). The incubation temperature was changed from $37^{\circ} \mathrm{C}$ to $33^{\circ} \mathrm{C}$ in order to standardize the growth of the strains.
Fluconazole (Zoltec, Pfizer, Guarulhos, SP, Brazil) was initially dissolved in sterile water in accordance with document M27A3 of the CLSI. ${ }^{14}$ Amphotericin B (Sigma, São Paulo, Brazil) was diluted in dimethyl sulfoxide (DMSO) (Vetec, Brazil). The serial dilutions of the antifungal agents were prepared in RPMI 1640 medium (with L-glutamine and without sodium bicarbonate) (MP Biomedicals, France), and were buffered to $\mathrm{pH} 7.0$ with $0.165 \mathrm{~mol} / \mathrm{l}$ morpholinopropane sulfonic acid (MOPS) (Êxodo Scientific, Brazil). The fluconazole concentration ranged from 0.0625 to $64 \mu \mathrm{g} / \mathrm{ml}$ and the final concentrations of amphotericin B ranged from 0.0312 to $16 \mu \mathrm{g} / \mathrm{ml}$. The Candida krusei strain ATCC 6258 were used as a quality control.

The minimum inhibitory concentration (MIC) results were defined for C. neoformans as specified by the CLSI ${ }^{14}$ and by other authors, as follows: MIC $>64 \mu \mathrm{g} / \mathrm{ml}$ was deemed to be resistant; MIC between 16 and $32 \mu \mathrm{g} / \mathrm{ml}$ was considered to be susceptible dose-dependent (SDD); and MIC $<8 \mu \mathrm{g} / \mathrm{ml}$ was considered to be susceptible. ${ }^{15,16}$

The interactions of simvastatin (Pharmanostra Ltda., São Paulo, Brazil) with amphotericin and of simvastatin with fluconazole were evaluated by means of the checkerboard microdilution method. ${ }^{17}$ The stock solution of simvastatin was prepared with DMSO at a concentration of $12800 \mu \mathrm{g} / \mathrm{ml}$ and was then diluted in RPMI 1640 medium buffered with MOPS in the proportions of 1:50. The final concentrations in the wells ranged from 128 to $0.25 \mu \mathrm{g} / \mathrm{ml}$. The interactions between these drugs were evaluated quantitatively by determining the fractional inhibitory concentration index (FICI). They were classified as synergistic if FICI $\leq 0.500$, indifferent if FICI $>0.500-4.0$ and antagonistic if FICI $>4.0 .{ }^{17,18}$ All the tests were performed in duplicate and on different days.

\section{RESULTS}

Isolates of Cryptococcus spp. were recovered from 30 of the 206 samples of dried feces from captive birds that were collected from pet shops (14.5\%). According to the bird species, the isolates of Cryptococcus spp. were recovered as follows: 28 (93.3\%) from Columbia livia, one (3.3\%) from Melopsittacus undulates and one (3.3\%) from Lonchura striata domestica. All of the isolates presented capsules, urease production, growth at $37{ }^{\circ} \mathrm{C}$ and melanin production on Niger seed agar. In addition, all of them presented a negative canavanine glycine bromothymol blue (CGB) test. According to the molecular typing, all the isolates of Cryptococcus neoformans were identified as VNI (Figure 1).

Ten isolates were selected to be subjected to the susceptibility tests. All of them presented susceptibility to amphotericin and fluconazole. On the other hand, all of these isolates presented MIC $>128 \mu \mathrm{g} / \mathrm{ml}$ in relation to simvastatin and, thus, were considered resistant in vitro to this drug. 
In the test on amphotericin B and simvastatin in combination, $6(60 \%)$ of the 10 isolates studied presented FICI $<0.500$, thus revealing a synergistic in vitro effect. Moreover, 3 samples (30\%) presented FICI values of 0.501 , i.e. only slightly above the cutoff value for synergism. Synergism between simvastatin and amphotericin B was detected at a simvastatin concentration of $0.250 \mu \mathrm{g} / \mathrm{ml}$. The isolates PI1543 and PI16202 showed MIC reductions from 1 $\mu \mathrm{g} / \mathrm{ml}$ to $0.250 \mu \mathrm{g} / \mathrm{ml}$, thus indicating clearly the synergistic effect of combining simvastatin with amphotericin B. However, when simvastatin was combined with fluconazole, no synergistic effect was observed (Table 1).

\section{DISCUSSION}

In the present study, Cryptococcus neoformans was isolated from $14.5 \%$ of the samples collected. Similar results were found in some other regions of Brazil: Cryptococcus neoformans was isolated in $17.3 \%$ of the captive birds droppings in a study in the city of Uberaba, Minas Gerais, and in $18.5 \%$ in the city of Salvador, Bahia. ${ }^{19,20}$ However, in other regions of Brazil, the prevalence has differed, ranging $25.3 \%$ in the southern region to $50 \%$ in the central region of this country. ${ }^{21}$ The variation in the isolation rates can be related to climatic factors, since high temperatures inhibit fungal growth. ${ }^{22}$ Additionally, the methodology

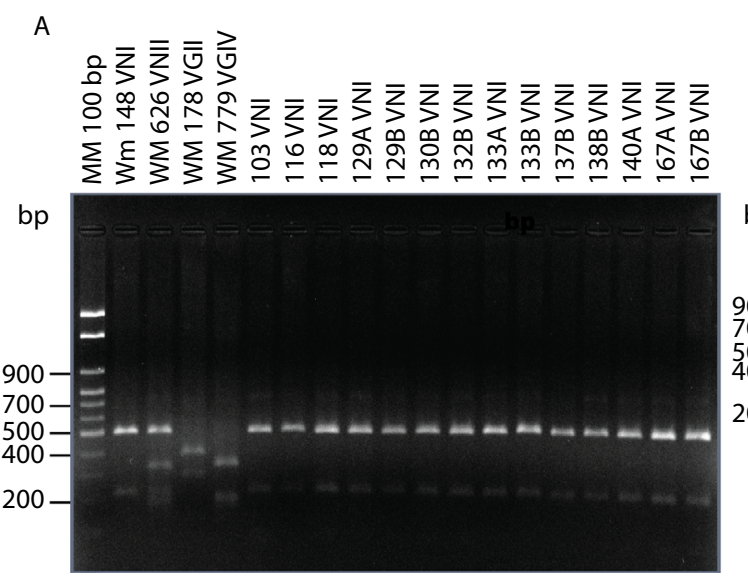

B

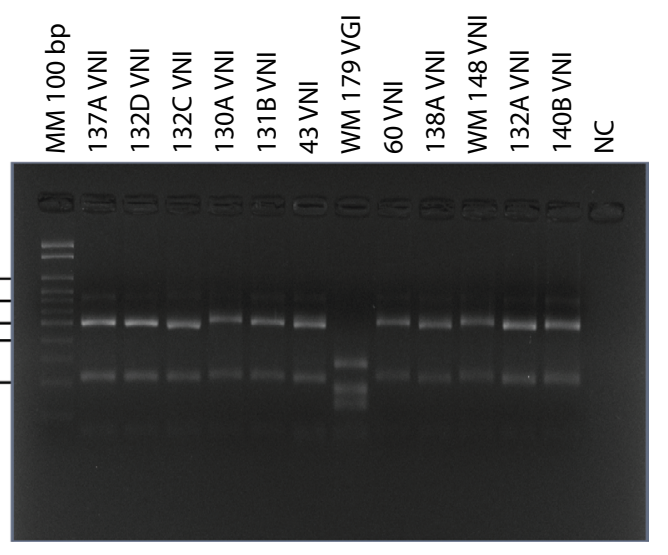

Figure 1. A: Representative agarose gel electrophoresis of URA5 polymerase chain reaction-restriction fragment length polymorphism showing the identification of molecular types VNI, VNII, VGII and VGIV (control samples) and the environmental Cryptococcus neoformans isolates of this study, all of genotype VNI (columns 6 to 19). MM: 100 bp molecular marker (column 1). B: Representative agarose gel electrophoresis of URA5 polymerase chain reaction-restriction fragment length polymorphism showing the identification of molecular types VNI and VGI (control samples) and the environmental Cryptococcus neoformans isolates of this study, all of genotype VNI (columns 2 to $7 ; 9$ and 10; 12 and 13). MM: 100 bp molecular marker (column 1). NC = negative control.

Table 1. Minimum inhibitory concentration (MIC), mean fractional inhibitory concentration index (FICI) and interactions of simvastatin (SIM) and amphotericin B (AMB) and fluconazole (FLZ) against environmental strains of Cryptococcus neoformans

\begin{tabular}{|c|c|c|c|c|c|c|c|c|c|c|c|c|}
\hline \multirow[b]{2}{*}{ Strain } & \multicolumn{12}{|c|}{ Minimum inhibitory concentration (MIC) } \\
\hline & $\begin{array}{c}\text { AMB } \\
(\mu \mathrm{g} / \mathrm{ml})\end{array}$ & $\begin{array}{c}A M B+S I M \\
(\mu \mathrm{g} / \mathrm{ml})\end{array}$ & $\begin{array}{c}\text { SIM } \\
(\mu \mathrm{g} / \mathrm{ml})\end{array}$ & $\begin{array}{c}\text { SIM + AMB } \\
(\mu \mathrm{g} / \mathrm{ml})\end{array}$ & $\begin{array}{c}\mathrm{FICl} \\
(\mathrm{AMB}+\mathrm{SIM})\end{array}$ & Interaction & $\begin{array}{c}\text { FLZ } \\
(\mu \mathrm{g} / \mathrm{ml})\end{array}$ & $\begin{array}{c}\mathrm{FLZ}+\mathrm{SIM} \\
(\mu \mathrm{g} / \mathrm{ml})\end{array}$ & $\begin{array}{c}\text { SIM } \\
(\mu \mathrm{g} / \mathrm{ml})\end{array}$ & $\begin{array}{c}\mathrm{SIM}+\mathrm{FLZ} \\
(\mu \mathrm{g} / \mathrm{ml})\end{array}$ & $\begin{array}{c}\mathrm{FICl} \\
(\mathrm{SIM}+\mathrm{FLZ})\end{array}$ & Interaction \\
\hline $\begin{array}{l}\text { Candida krusei } \\
\text { ATCC } 6258\end{array}$ & 1.0 & $\mathrm{~N} / \mathrm{A}$ & $>128$ & $\mathrm{~N} / \mathrm{A}$ & N/A & $\mathrm{N} / \mathrm{A}$ & 32 & N/A & $>128$ & N/A & $\mathrm{N} / \mathrm{A}$ & $\mathrm{N} / \mathrm{A}$ \\
\hline PI1543 & 1.0 & 0.250 & $>128$ & 0.250 & 0.251 & Synergism & 8 & 64 & $>128$ & $>128$ & 9 & Antagonism \\
\hline PI1544 & 0.25 & 0.125 & $>128$ & 0.250 & 0.501 & Indifferent & 8 & 64 & $>128$ & $>128$ & 9 & Antagonism \\
\hline PI16198 & 0.5 & 0.125 & $>128$ & 0.250 & 0.251 & Synergism & 8 & 64 & $>128$ & $>128$ & 9 & Antagonism \\
\hline PI16199 & 0.5 & 0.500 & $>128$ & 0.250 & 1.000 & Indifferent & 8 & 64 & $>128$ & 0.25 & 8 & Antagonism \\
\hline PI16200 & 0.5 & 0.250 & $>128$ & 0.250 & 0.501 & Indifferent & 8 & 64 & $>128$ & $>128$ & 9 & Antagonism \\
\hline PI16202 & 1.0 & 0.250 & $>128$ & 0.250 & 0.251 & Synergism & 8 & 8 & $>128$ & 1 & 1 & Indifferent \\
\hline PI17123 & 0.5 & 0.125 & $>128$ & 0.250 & 0.251 & Synergism & 8 & 64 & $>128$ & $>128$ & 9 & Antagonism \\
\hline
\end{tabular}

$\mathrm{N} / \mathrm{A}=$ not applicable; $\mathrm{AMB}=$ amphotericin $\mathrm{B} ; \mathrm{SIM}=$ simvastatin; FLZ = fluconazole; $\mathrm{FICI}=$ fractional inhibitory concentration index. 
used and conditions of bird rearing may interfere with the isolation rates. ${ }^{21}$

Cryptococcus neoformans and Cryptococcus gattii have at least eight different molecular types that present variable geographical distribution within the eco-epidemiological context of the disease in Brazil and worldwide. The isolates of the present study were identified as the VNI genotype. This result was concordant with what has previously been found in Brazil and other parts of the world: in previous studies, the VNI genotype was detected in $95 \%$ of the environmental samples in which Cryptococcus neoformans was identified. ${ }^{19}$ The predominance of the VNI genotype among the isolates recovered also enables better interpretation of the antifungal susceptibility test, given the consequent homogeneity of the population. On the other hand, it is well known that certain genotypes, such as VNIV, can frequently be recovered from regions such as around the Mediterranean basin. ${ }^{23}$

The susceptibility profile of Cryptococcus spp. relating to antifungals was evaluated in different countries between 1990 and 2004. The resistance to amphotericin B, 5-flucytosine and fluconazole that was detected was less than $1 \%$. Isolates from North America presented $\mathrm{MIC} \leq 8 \mu \mathrm{g} / \mathrm{ml}$ in relation to fluconazole, while in other geographical regions (Latin America and Africa), the strains showed susceptibility to fluconazole in $94 \%$ to $100 \%$ of the cases. Additionally, the isolates presented $99 \%$ susceptibility to amphotericin B, with $\mathrm{MIC} \leq 1 \mu \mathrm{g} / \mathrm{ml}^{2}{ }^{24}$

There is increasing interest in evaluating the antifungal activity of antifungal drugs, especially in the field of combined therapy. ${ }^{25}$ In addition, evidence demonstrating the potential use of statins for preventing and treating infections has been reported. Statins have been shown to attenuate the pathogenicity of microorganisms through modulating the signaling and other regulatory pathways that are involved in the infection..$^{26,27}$ The activity of statins against Cryptococcus and Candida species, with particular emphasis on simvastatin, used in isolation or in combination with classical antifungals such as amphotericin B and fluconazole, was previously described by Brilhante et al. ${ }^{10}$ Chin et al. ${ }^{9}$ demonstrated that the statin fluvastatin had fungicidal action against different species of Candida. Moreover, a synergistic effect was observed through combinations of fluvastatin with fluconazole and itraconazole, two commonly used azole compounds. With these combinations, both fluconazole and itraconazole exhibited potent activity against species of Candida and also against Cryptococcus neoformans.

The in vitro interactions of the effects of various statins, including simvastatin and various azole antifungals, against different opportunistic pathogenic fungi such as Candida and Aspergillus species, were investigated in another study. Fluconazole was found to act synergistically against Aspergillus fumigatus in combination with simvastatin, lovastatin and atorvastatin. The interaction of the combination of miconazole and simvastatin against Candida glabrata was not significant, but the sensitivities to this azole compound differed by one or two dilution steps between the isolates. ${ }^{28}$

The results from the present study demonstrated the efficacy of simvastatin as a synergistic agent in combination with amphotericin B against environmental isolates of Cryptococcus neoformans. However, no inhibition of yeast growth was observed when the effect of simvastatin was evaluated in isolation or in combination with fluconazole, and the MIC values found were elevated. Similar results were demonstrated by Brilhante et al., ${ }^{10}$ such that all the strains of Cryptococcus neoformans evaluated were inhibited by the combination of simvastatin and amphotericin B. However, no such inhibition was observed in relation to the combination of simvastatin and fluconazole.

The antifungal effect observed when simvastatin was evaluated in combination with amphotericin B may have been due to the action of statins in the process of formation of ergosterol, which has similarity to human cholesterol. This drug acts by inhibiting 3-hydroxy-3-methyl-glutaryl-coenzyme-A (HMG-CoA) reductase in both humans and fungi, since both of these act on the same synthetic pathway as mevalonate. The in vitro activity of statins (fluvastatin, simvastatin, pravastatin and lovastatin) against strains of species of Candida and Cryptococcus was evaluated, and only fluvastatin demonstrated inhibition of these yeasts. However, in vitro interaction of fluvastatin with fluconazole and amphotericin B has been observed, which demonstrates the potential synergism between these drugs. ${ }^{9}$

It is important to note that, in the present study, two isolates had a MIC of $1.0 \mu \mathrm{g} / \mathrm{ml}$ for amphotericin B, which was the highest MIC among the strains evaluated. These isolates presented a considerable reduction in MIC $(0.250 \mu \mathrm{g} / \mathrm{ml})$ when the combination of amphotericin B and simvastatin was tested, which again emphasizes the potential use of this combination of these drugs. On the other hand, among the four isolates presenting indifferent results regarding the association between amphotericin $B$ and simvastatin, three of them demonstrated values that were slightly above the cutoff that had been adopted.

Given that all of the isolates of the present study belonged to the same molecular type, it is possible that a greater number of samples tested would have enabled clear demonstration of the synergistic effects between these two drugs. However, we collected the number of samples that were available at the time when the study was performed (i.e. 206 samples). Our isolation rate of $14.5 \%$ was in line with what had been found in other studies using the same methodology ${ }^{19,20}$ On the other hand, increasing the number of samples would also potentially have led to greater variability of the fungi in the samples (there are eight molecular types of Cryptococcus).

\section{CONCLUSION}

The data of this study demonstrate that simvastatin should be considered to be a possible therapeutic alternative, with the capacity to 
potentiate the action of amphotericin B. Through using this drug, the duration of cryptococcosis treatment could potentially become shorter and, consequently, the time for which patients are exposed to the toxic effects of this antifungal could be reduced. In addition, statins may have an important role in the future, as a new treatment alternative in situations of resistance to antifungals.

\section{REFERENCES}

1. Archibald LK, Tuohy MJ, Wilson DA, et al. Antifungal susceptibilities of Cryptococcus neoformans. Emerg Infect Dis. 2004;10(1):143-5. PMID: 15078612; doi: 10.3201/eid1001.020779.

2. Park YD, Sun W, Salas A, et al. Identification of multiple cryptococcal fungicidal drug targets by combined gene dosing and drug affinity responsive target stability screening. MBio. 2016;7(4). pii: e01073-16. PMID: 27486194; doi: 10.1128/mBio.01073-16.

3. Tewari A, Behera B, Mathur P, Xess I. Comparative analysis of the Vitek 2 antifungal susceptibility system and E-test with the CLSI M27-A3 broth microdilution method for susceptibility testing of Indian clinical isolates of Cryptococcus neoformans. Mycopathologia. 2012;173(5-6):427-33. PMID: 22354778; doi: 10.1007/s1 1046-012-9528-9.

4. Chandenier K, Adou-Bryn KD, Douchet C, et al. In vitro activity of amphotericin $B$, fluconazole and voriconazole against 162 Cryptococcus neoformans isolates from Africa and Cambodia. Eur J Clin Microbiol Infect Dis. 2004;23(6):506-8. PMID: 15141336; doi: 10.1007/s10096-004-1136-2.

5. Almeida AM, Matsumoto MT, Baeza LC, et al. Molecular typing and antifungal susceptibility of clinical sequential isolates of Cryptococcus neoformans from São Paulo State, Brazil. FEMS Yeast Res. 2007;7(1):152-64. PMID: 17311593; doi: 10.1111/j.1567-1364.2006.00128.x.

6. Ferreira-Paim K, Andrade-Silva L, Mora DJ, et al. Antifungal susceptibility, enzymatic activity, PCR fingerprinting and ITS sequencing of environmental Cryptococcus laurentii isolates from Uberaba, Minas Gerais, Brazil. Mycopathologia. 2012;174(1):41-52. PMID: 22116628; doi: 10.1007/s11046-011-9500-0.8.

7. Scorzoni L, Paula e Silva ACA, Marcos CM, et al. Antifungal therapy: new advances in the understanding and treatment of mycosis. Front Microbiol. 2015;8(36):1-23. PMID: 28167935; doi: 10.3389/fmicb.2017.00036.

8. Liao JK, Laufs U. Pleiotropic effects of statins. Annu Ver Pharmacol. 2005;45:89-118. PMID: 15822172; doi: 10.1146/annurev. pharmtox.45.120403.095748.

9. Chin NX, Weitzman I, Della-Latta P. In vitro activity of fluvastatin, a cholesterol-lowering agent, and synergy with fluconazole and itraconazole against Candida species and Cryptococcus neoformans. Antimicrob Agents Chemother. 1997;41(4):850-2. PMID: 9087504.

10. Brilhante RS, Caetano EP, Oliveira JS, et al. Simvastatin inhibits planktonic cells and biofilms of Candida and Cryptococcus species. Braz J Infect Dis. 2015;19(5):459-65. PMID: 26119850; doi: 10.1016/j.bjid.2015.06.001.

11. Randhawa HS, KowshikT, Khan ZU. Efficacy of swabbing versus a conventional technique for isolation of Cryptococcus neoformans from decayed wood in tree trunk hollows. Med Mycol. 2005;43(1):67-71. PMID: 15712609.
12. Bolano A, Stinchi S, Preziosi R, et al. Rapid methods to extract DNA and RNA from Cryptococcus neoformans. FEMS Yeast Res. 2001;1 (3): 221-4. PMID: 12702347; doi: 10.1111/j.1567-1364.2001.tb00037.x.

13. MeyerW, Castaneda A, Jackson S, et al. Molecular typing of IberoAmerican Cryptococcus neoformans isolates. Emerg Infect Dis. 2003;9(2):189-95. PMID: 12603989; doi: 10.3201/eid0902.020246.

14. Clinical Laboratory Standard Institute (CLSI). Reference method for broth dilution antifungal susceptibility testing of yeasts; approved standards-Third edition. 2008;28(14):M27-A3. ISBN: 1-56238-666-2.

15. Souza LK, Fernandes Ode F, Kobayashi CC, et al. Antifungal susceptibilities of clinical and environmental isolates of Cryptococcus neoformans in Goiania city, Goias, Brazil. Rev Inst Med Trop Sao Paulo. 2005;47(5):253-6. PMID: 16302107; doi: 10.1590/S0036-46652005000500003.

16. Leão CA, Ferreira-Paim K, Andrade-Silva L, et al. Primary cutaneous cryptococcosis caused by Cryptococcus gattii in an immunocompetent host. Med Mycol. 2011;49(4):352-5. PMID: 21028946; doi: 10.3109/13693786.2010.530697.

17. Cuenca-Estrella M. Combinations of antifungal agents in therapy-what value are they? J Antimicrob Chemother. 2004;54(5):854-869. PMID: 15375111; doi: 10.1093/jac/dkh434.

18. Odds FC. Synergy, antagonism, and what the chequerboard puts between them. J Antimicrob Chemother. 2003;52(1):1. PMID: 12805255; doi: 10.1093/jac/dkg301.

19. Ferreira-Paim K, Andrade-Silva L, Mora DJ, et al. Genotyping of Cryptococcus neoformans isolated from captive birds in Uberaba, Minas Gerais, Brazil. Mycoses. 2010;54(5):e294-300. PMID: 20492533; doi: 10.1111/j.1439-0507.2010.01901.x.

20. Costa AK, Sidrim JJ, Cordeiro RA, et al. Urban pigeons (Columba livia) as a potential source of pathogenic yeasts: a focus on antifungal susceptibility of Cryptococcus strains in Northeast Brazil. Mycopathologia. 2010;169(3):207-13. PMID: 19847668; doi: 10.1007/s1 1046-009-9245-1.

21. Lugarini C, Condas LAZ, Soresini GCG, et al. Screening of antigenemia and isolation of Cryptococcus neoformans and Cryptococcus gattii from cloaca and crop of birds in the state of Paraná, Brazil. Pesqu Vet Bras. 2008;28(7):341-4. doi: 10.1590/S0100-736X2008000700004.

22. Casali AK, Goulart L, Rosa e Silva LK, et al. Molecular typing of clinical and environmental Cryptococcus neoformans isolates in the Brazilian state Rio Grande do Sul. FEMS Yeast Res. 2003;3(4):405-15. PMID: 12748052; doi: 10.1016/S1567-1356(03)00038-2.

23. Cogliati M, D'Amicis R, Zani A, et al. Environmental distribution of Cryptococcus neoformans and C. gattii around the Mediterranean basin. FEMS Yeast Res. 2016;16(4). pii: fow045. PMID: 27188887; doi: 10.1093/femsyr/fow045.

24. Pfaller MA, Boyken L, Hollis RJ, et al. In vitro susceptibilities of clinical isolates of Candida species, Cryptococcus neoformans, and Aspergillus species to itraconazole: global survey of 9,359 isolates tested by clinical and laboratory standards institute broth microdilution methods. J Clin Microbiol. 2005;43(8):3807-10. PMID: 16081915; doi: 10.1128/ JCM.43.8.3807-3810.2005. 
25. Galgóczy L, Papp T, Kovács L, Ordögh L, Vágvölgyi C. In vitro activity of phenothiazines and their combinations with amphotericin B against Zygomycetes causing rhinocerebral zygomycosis. Med Mycol. 2009;47(3):331-5. PMID: 18798117; doi: 10.1080/13693780802378853.

26. Falagas ME, Makris GC, Matthaiou DK, Rafailidis PI. Statins for infection and sepsis: a systematic review of the clinical evidence. J Antimicrob Chemother. 2008;61 (4):774-85. PMID: 18263570; doi: 10.1093/jac/dkn019.

27. Sun HY, Singh N. Antimicrobial and immunomodulatory attributes of statins: relevance in solid organ transplant recipients. Clin Infect Dis. 2009;48(6):745-55. PMID: 19193110; doi: 10.1086/597039.

28. Nyilasi I, Kocsubé S, Krizsán K, et al. In vitro synergistic interactions of the effects of various statins and azoles against some clinically important fungi. FEMS Microbiol Lett. 2010;307(2):175-84. PMID: 20636975; doi: 10.1111/j.1574-6968.2010.01972.x.

Authors' contributions: Tássio Henrique Sousa Silva, Claudiane Vansoski Araújo, Khelvin Myner da Costa Santos, Nathanael dos Santos Alves, Thayse Haylene Soares Gomes, Andressa Kelly Ferreira e Silva and Nayra Cristina Lira dos Santos Silva: collected the samples, isolated the fungus and did phenotype and genotype identification; Evandro César Bezerra Damasceno Júnior, Andressa Maria Aguiar de Carvalho, Maria Gabriela Araújo Mendes and Henrique Barros Caminha: conducted susceptibility tests on antifungals and statins, interpreted the data, analyzed the data and critically reviewed the manuscript; Thatiana Bragine Ferreira and Leonardo Eurípedes Andrade-Silva: performed DNA extraction, performed RFLP, did genotype identification on the isolates and reviewed the manuscript; Tatiane Caroline Daboit and Mário León Silva-Vergara: conducted critical reviews on the study, designed the study, interpreted the data and analyzed the data; Kennio Ferreira-Paim and Fernanda Machado Fonseca: conceptualized the study, devised the study design, performed data analysis and writing, did critical review on the manuscript and approved the final version of the manuscript

\section{Sources of funding: None \\ Conflict of interest: None}

Date of first submission: February 22, 2019

Last received: July 16, 2019

Accepted: September 16, 2019

\section{Address for correspondence:}

Fernanda Machado Fonseca

Instituto de Ciências da Saúde (ICS), Departamento de Biomedicina, Universidade Federal do Triângulo Mineiro (UFTM)

Av. Getúlio Guaritá, 130

Uberaba (MG) - Brasil

CEP 38025-440

Tel. (+55 34) 3700-6819

E-mail: fernanda.fonseca@uftm.edu.br 